\title{
Mixoma de atrio izquierdo sobre el ligamento de Marshall: un representativo inusual o infrecuente
}

\author{
Left atrium mixoma on Marshall's ligament: an unusual or uncommon representative \\ Gutenberg Navarro-Zambrano*, Samuel Ramírez-Marroquín, Felipe Santibáñez-Escobar y \\ Guillermo Castro-Lozano \\ Departamento de Cirugía Cardiotorácica, Instituto Nacional de Cardiología Ignacio Chávez, Facultad de Medicina, Universidad Nacional Autónoma \\ de México, Ciudad de México, México
}

El mixoma auricular es un tumor cardiaco primario, común y benigno, que se asocia a complicaciones que dependerán de su ubicación ${ }^{1}$. Los mixomas auriculares izquierdos son más frecuentes que los derechos (5:1). El $85 \%$ se localizan en el tabique interauricular izquierdo, el $11 \%$ en el tabique auricular derecho y el $1 \%$ son múltiples ${ }^{2,3}$.

Un caso infrecuente de mixoma es el localizado en el ligamento de Marshall, no reportado en la literatura, con alto riesgo de evento cerebrovascular isquémico posterior a embolización, que se puede manifestar clínicamente y debe ser considerado en el diagnóstico diferencial para su detección, identificación y tratamiento oportuno. Se presenta el caso de una paciente de 64 años, con antecedentes patológicos de taquicardia supraventricular, datos clínicos de accidente isquémico transitorio y una angiotomografía coronaria que como hallazgo incidental muestra la presencia de un tumor (mixoma) o un trombo en la aurícula izquierda. Se realizó ecocardiograma transesofágico que evidenció un tumor en la aurícula izquierda sugestivo de mixoma $(22 \times 23 \mathrm{~mm})$, heterogéneo, con bordes definidos, ligeramente móvil, sobre el ligamento de Marshall, cercano a la orejuela de la aurícula izquierda (Fig. 1). Se decidió tratamiento quirúrgico mediante exéresis, por esternotomía media y atriotomía izquierda. Los hallazgos fueron: tumor en la aurícula izquierda de $2.4 \times 2.4 \mathrm{~mm}$ adherido al ligamento de Marshall (Fig. 2). El estudio histopatológico diagnosticó un mixoma. La paciente evolucionó favorablemente con 24 horas de estancia en cuidados intensivos y egreso hospitalario a los 6 días.

\section{Financiamiento}

Ninguno.

\section{Conflicto de intereses}

Ninguno.

\section{Responsabilidades éticas}

Protección de personas y animales. Los autores declaran que para esta investigación no se han realizado experimentos en seres humanos ni en animales.

\section{Correspondencia:}

*Gutenberg Navarro-Zambrano

E-mail: gutenbergnavarro@gmail.com
Fecha de recepción: 01-05-2020

Fecha de aceptación: 17-08-2020 DOI: 10.24875/ACM.20000194
Disponible en internet: $15-10-2020$ Arch Cardiol Mex. 2021;91(3):364-365 www.archivoscardiologia.com CC BY-NC-ND (http://creativecommons.org/licenses/by-nc-nd/4.0/). 


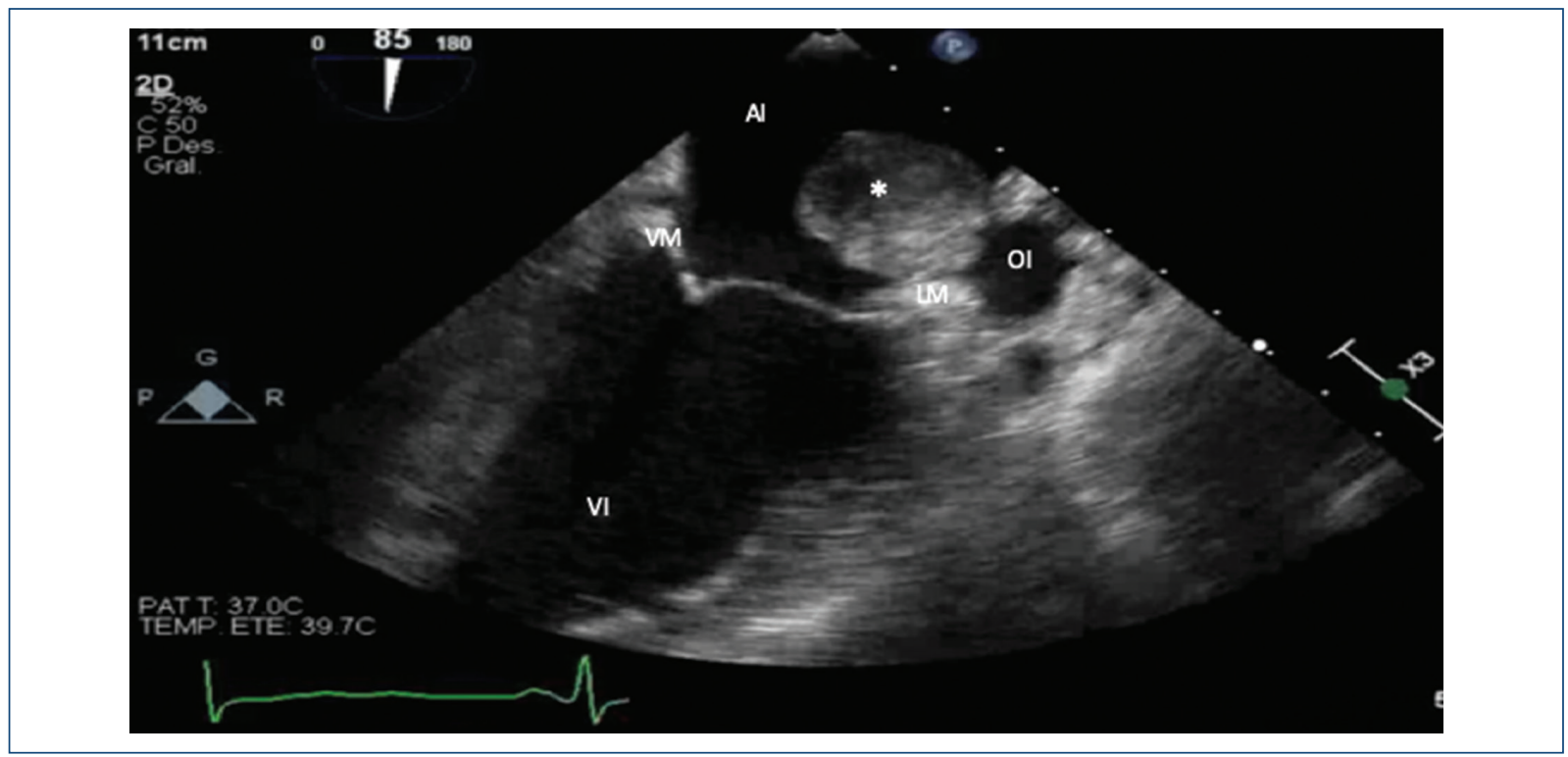

Figura 1. Ecocardiograma transesofágico que evidenció una masa en la aurícula izquierda de $22 \times 23 \mathrm{~mm}$ ubicada sobre el ligamento de Marshall (asterisco), compatible con mixoma. Al: aurícula izquierda; LM: ligamento de Marshall; VI: ventrículo izquierdo.

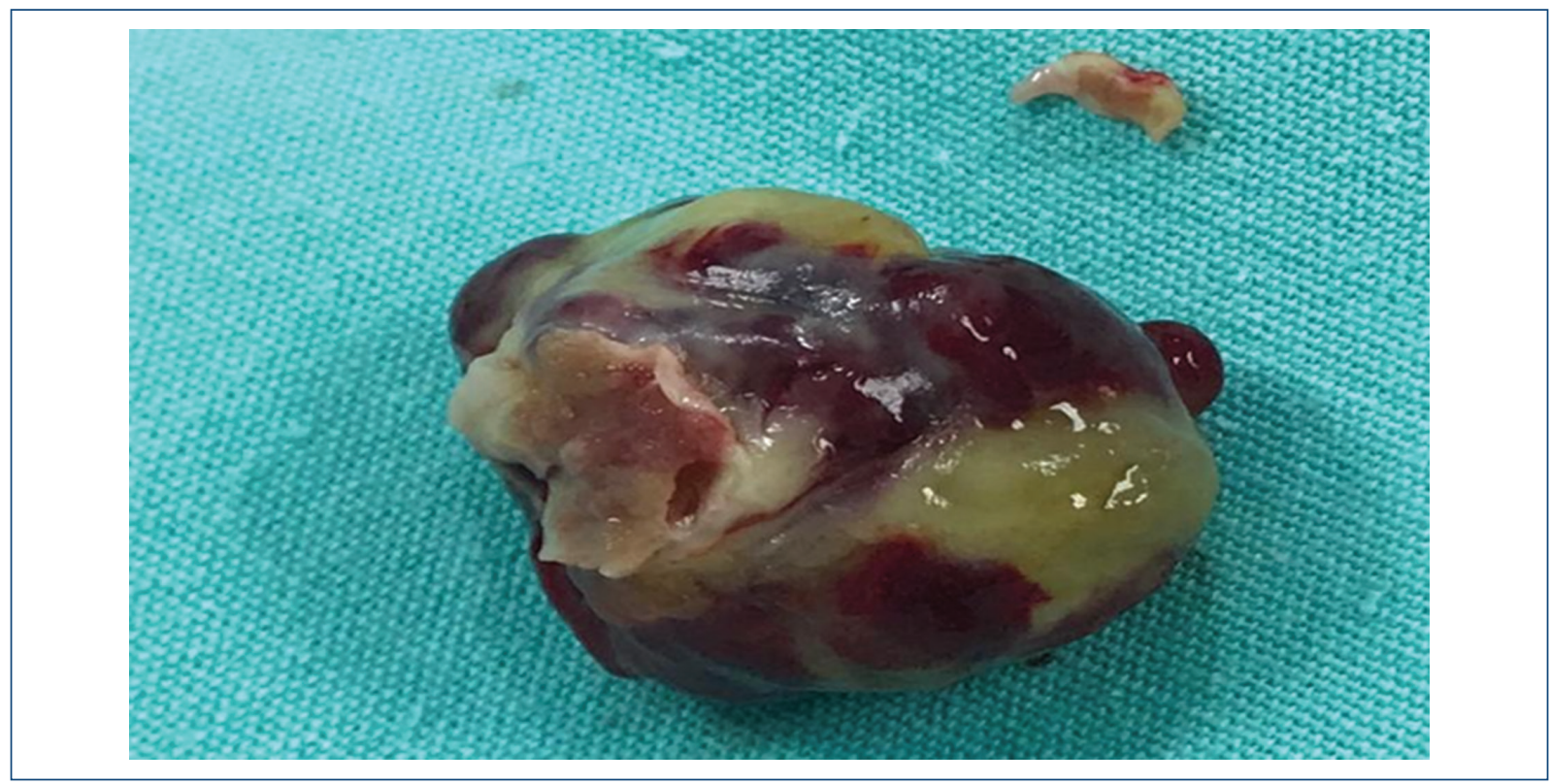

Figura 2. Visión macroscópica del mixoma de aurícula izquierda, de $24 \times 24 \mathrm{~mm}$, ubicado sobre el ligamento de Marshall.

Confidencialidad de los datos. Los autores declaran que han seguido los protocolos de su centro de trabajo sobre la publicación de datos de pacientes.

Derecho a la privacidad y consentimiento informado. Los autores declaran que en este artículo no aparecen datos de pacientes.

\section{Bibliografía}

1. Burgos E, Bermúdez J, Chávez W. Mixoma auricular relacionado con evento cerebrovascular vascular isquémico. Med Clin (Barc). 2018;151: e69-e70.

2. Ihsen Z, Hela M, Khadija M, Zouhayer J. Cerebral embolism complicating left atrial myxoma: a case report. Pan Afr Med J. 2016;24:140.

3. Yin W, Xian F, Xiao L, Xinmin Z. Stroke and peripheral embolisms in a pediatric patient with giant atrial myxoma: case report and review of current literature. Medicine (Balt). 2018;97:e11653. 